\title{
Study the release kinetics of curcumin released from PVA/curcumin composites and its evaluation towards hepatocarcinoma
}

\author{
Doaa Essamey El-Nashar ${ }^{1 *}$, Nehad Naem Rozik ${ }^{1}$, Abdel Mohsen Soliman ${ }^{2}$, Fahima Helaly ${ }^{1}$ \\ ${ }^{1}$ Polymer \& Pigments Department, National Research Centre, Giza, Egypt. \\ ${ }^{2}$ Therapeutic Chemistry Department, National Research Centre, Giza, Egypt.
}

\begin{tabular}{|c|c|}
\hline ARTICLE INFO & ABSTRACT \\
\hline $\begin{array}{l}\text { Article history: } \\
\text { Received on: } 25 / 04 / 2016 \\
\text { Revised on: } 25 / 05 / 2016 \\
\text { Accepted on: } 19 / 06 / 2016 \\
\text { Available online: } 28 / 07 / 2016\end{array}$ & $\begin{array}{l}\text { The polymer composites based on Polyvinyl alcohol loaded with different concentrations of commercial } \\
\text { curcumin were prepared to be applied forcontrolled release drug delivery system to overcome the growth } \\
\text { promotion of tumor cells. The prepared composites were subjected to drug release in aqueous media at room } \\
\text { temperature. It was found that the amount of the released curcumin changed according to different } \mathrm{pH} \text { media } \\
\text { and the concentration of the loaded drug onto the polymer carrier. The diffusion coefficient of the released }\end{array}$ \\
\hline $\begin{array}{l}\text { Key words: } \\
\text { Curcumin, Polyvinyl alcohol } \\
\text { (PVA), slow release, } \\
\text { anticancer drug. }\end{array}$ & $\begin{array}{l}\text { acidic and neutral solution respectively according to Higuch's equation. The results of the in/vitro cytotoxic } \\
\text { activity of the released curcumin showed sustained antiproliferative potency up to } 30 \% \text { growth inhibition } \\
\text { against the human liver cancer cell line (HEPG2) which extended to } 25 \text { days, to overcome hepatocarcinoma. }\end{array}$ \\
\hline
\end{tabular}

\section{INTRODUCTION}

The polymer composites were developed as drug carriers for along time ago.Their applications have tremendously enlarged due to their enhanced loadingpossibilities, stability and the control of the physicochemical properties (Parida et al., 2011; Sahoo et al., 2010). Ideally, polymer composites played a considerable role because it can deliver directly to the targeted site with outstanding efficacy. The localized drug release may be carried outusing macroscopic loaded drug close to the target site. For this approach, in-situ forming biomaterials in response to environmental stimuli have gained significant attention, due to the expanded properties, the decreaseof side effects related toregular administration, and improve the biodistribution of the drug (Mallapragada and Peppas, 1996; Helaly et al., 2015). Polyvinyl alcohol (PVA) is not only considered as a nontoxic hydrophilicpolymer but alsoit is a water soluble and has the ability for thefilm-forming. Likewise, it has a good physical and

\footnotetext{
* Corresponding Author

Doaa E El.Nashar, Polymer \& Pigments Department, National Research Centre, Giza, Egypt.Email:doaaelnashar@yahoo.com
}

chemical properties (Chandy and Sharma, 1992 ). It is attracted tremendous attention due to high hydrophilicity, flexibility, and biocompatibility. PVA has advantages of being a host polymer due to its cost effectiveness, availability, good optical properties, high hydrophilicity, non-toxicity and good mechanical strength as well as high-temperature resistance. Other reasons for choosing PVA as host polymer are the greater extent of polar groups (hydroxyl group) and high chain flexibility (Clemons et al., 2013). Curcumin is a phytochemical compound used as antioxidant, antiinflammatory, and anticarcinogenic activities (Cikrikci et al., 2008; Nagpal and Sood, 2013). Curcumin is obtained from the rhizome of the plant Curcuma longa, its color is golden yellow. It can be applied for varioustherapeutic effects due to their outstanding properties (Sharma et al., 2012; Ravichandran, 2013; Dutta and Ikiki, 2013). Curcumin has shown a variety of biological activity for various human diseases including cancer in thepreclinical setting. Its poor oral bioavailability shows significant pharmacological barriers to its clinical application (Douglass and Clouatre, 2015). The curcumin is hydrophobic in nature and has an absorption band at awavelength around $420 \mathrm{~nm}$ (Steffi and Srinivasan, 2014; Mandal et al., 2007). 
The aim of the present work focus on film prepared frompoly (vinyl alcohol) (PVA)/curcumin composites by solution casting technique. Study the release rate of curcumin at different aqueous media as well as the release kinetics and diffusion mechanism according to Fick's law. Also, study the cytotoxic potency against the human liver cancer cell line (HEPG2).

\section{MATERIALS AND METHODS}

\section{Materials}

Commercial Curcumin, tetrahydrofuran (THF), was supplied by BASF (Ludwigshafen, Germany). Polyvinyl alcohol (PVA) purchased from Aldrich Co., Germany and Pluronic was purchased from BASAF as a surfactant.

- Sulfuric acid with density $1.84 \mathrm{~g} \mathrm{~cm}^{-3}$ and boiling point $337{ }^{\circ} \mathrm{C}$ was supplied by Aldrich Company, Germany.

- Sodium hydroxide pellets are odorless, white, solid hemispheres of uniform diameter and thickness with melting point $318.4{ }^{\circ} \mathrm{C}$ was supplied by Sigma-Aldrich.

\section{Preparation of films with drug loading}

The PVA was dissolved in aqueous solution by using $\mathrm{THF}$, heated in a water bath and stirred for $30 \mathrm{~min}$. The solution was casted into a Petri dish and different concentrations of curcumin 1, 2 and $3 \%$ w/w solid were added to the PVA solution, all the samples were prepared in the presence of a pluronic surfactant. The resulting solution was stirred thoroughly for few hours until a homogeneous yellow color solution is obtained. The solution was eventually poured on glass Petri dish and dried in an oven at $60^{\circ} \mathrm{C}$ to obtain a free-standing film. The structure formula of curcumin is shown in Figure 1 in the enol and diketones forms.

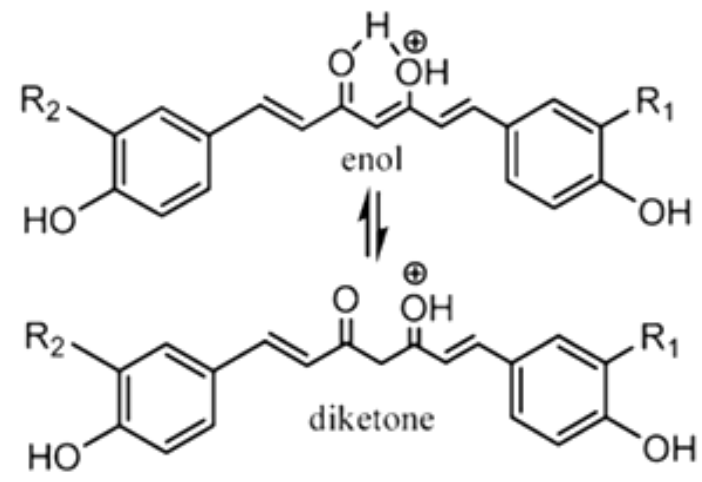

Fig. 1: The structure of Curcumin.

\section{Drug Release Mechanism from Matrices}

From time to time, various authors have proposed several types of drug release mechanisms from matrices. It has been proposed that drug release from matrices usually implies water penetration in the matrix, hydration, swelling, diffusion of the dissolved drug (polymer hydro fusion), and/or the erosion of the gelatinous layer. Several kinetic models relating to the drug release from matrices, selected from the most important mathematical models, as illustrated equations from (1-7). However, it is worth to mention that the release mechanism of a drug would depend on the dosage from selected polymer, $\mathrm{pH}$ of aquatic media, and nature of the drug and polymer type.

1. Zero - Order Kinetics (Xu and Sunada, 1995). $W=K 1 t$

2. First - Order Kinetics (Xu and Sunada, 1995, Ritger and Peppas, 1987).

$$
\operatorname{Ln}(100-W)=\operatorname{Ln} 100-k 2 t
$$

3. Hixon-Crowel's Cube- Root Equation (Erosin Model) (Ritger and Peppas, 1987).

$$
(100-W) 1 / 3=1001 / 3-k 3 t
$$

4. Higuchi's Square Root of Time Equation (Diffusion Model) (Higuchi, 1963).

$$
W=k 4 t
$$

5. Power Law Equation (Diffusion/ Relaxation model) (Kulkarni et al., 1999).

$$
M t / M \infty=k 5 t n
$$

The empirical equation for analyzing both Fickian and non-Fickian release of drug from polymeric delivery systems is represented as (Chime et al., 2013):

$$
M t / M \infty=k t n
$$

The logarithm form of equation 6 could be written as:

$$
\log (M t / M \infty)=\log k+n \log t
$$

Where $\mathrm{Mt} / \mathrm{M} \infty$ is a fraction of drug released at time $\mathrm{t}, \mathrm{n}$ is diffusion exponent indicative mechanism of transport drug through the polymer, $\mathrm{K}$ is kinetic constant depends on incorporating structure and geometric characteristics of the delivery system. The release exponent $\mathrm{n} \leq 0.5$ accordingto Fickian diffusion release from the slab, $0.5<\mathrm{n}<1.0$ for non-Fickian release (anomalous), this means that drug release followed both diffusion and erosion controlled mechanism and $\mathrm{n}=1$ for zero order release, where drug release is independent of time as described previously (Parida et al., 2011, Chime et al., 2013). Also, $0.45<\mathrm{n}<1.0$ for non-Fickian release (anomalous) and $0.43<\mathrm{n}<1.0$ for non-Fickian release (anomalous).

\section{Characterization techniques \\ Fourier-transform infrared (FTIR) spectroscopy}

The FTIR spectra of samples were obtained using a Jascow (Japan) FTIR 430 series infrared spectrophotometer equipped with $\mathrm{KBr}$ discs.

\section{Leaching rate}

The leaching rate technique used was similar to that described by Marson 1969. The prepared composites of poly (vinyl alcohol) (PVA)/ curcumin were used in the form of films of $1 \times 0.5 \times 1.5 \mathrm{~mm}$ side lengths and total surface area of about 5.5 $\mathrm{mm}^{2}$. Each sample was immersed in $50 \mathrm{ml}$ of different aquatic media, distilled water, acidic and alkaline solutions, at room temperature and it was kept at specific $\mathrm{PH}$. The amount of drug released was determined spectrophotometrically at a wavelength $416 \mathrm{~nm}$ for the investigated drug in distilled water, acidic and 
alkali solutions, respectively. The used spectrophotometer was UV-240 1PC Visible VIS. The calibration standard is shown in Figure 2.

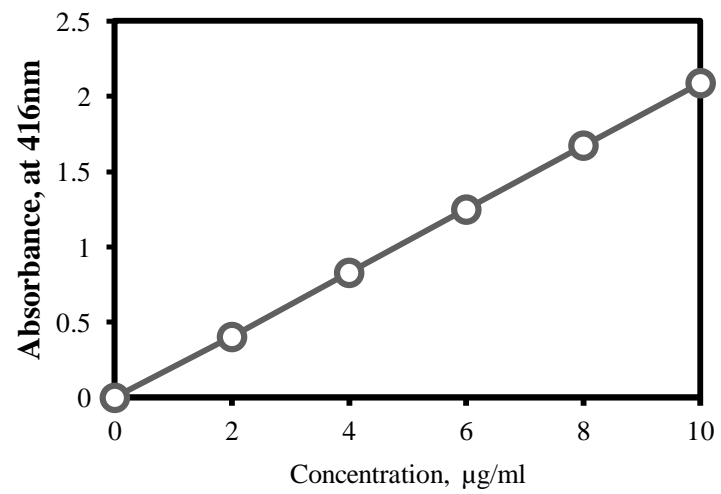

Fig. 2: The standard curve of curcumin at absorbance $416 \mathrm{~nm}$

\section{Anti-proliferative assay of the released curcumin against HEPG2 cell line}

Measurement of potential cytotoxicity was done using SRB assay (Skehan et al., 1990). The timely released curcumin was subjected to a screening system for evaluation of its antiproliferative activity against human liver cancer cell line HEPG2.

\section{RESULTS AND DISCUSSIONS}

\section{FTIR Spectroscopy}

FTIR was utilized to evaluate the prepared polymer composites. In Figure 3, the strong peak observed at the range of $800-1100 \mathrm{~cm}^{-1}$ which was corresponding to the stretching mode of vinyl bonds.

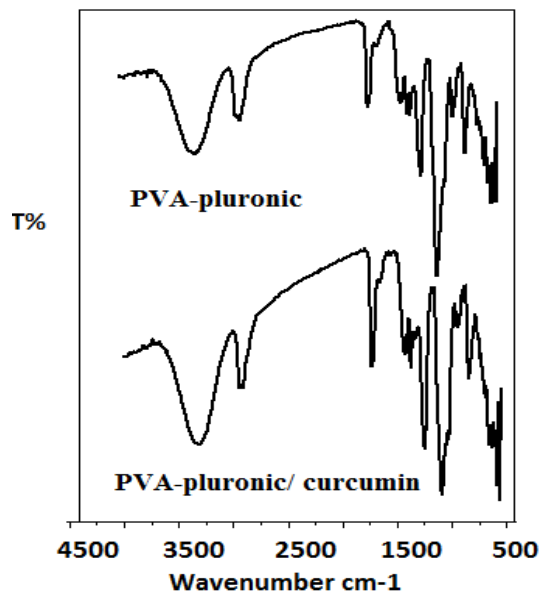

Fig 3: The FTIR of PVA-pluronic/curcumin

The $-\mathrm{CH}$ stretching vibration of the polymer backbone is manifested through peaks at 2936- $2969 \mathrm{~cm}^{-1}$.

The peak at 1625 and $3407 \mathrm{~cm}^{-1}$ corresponding to $\mathrm{C}=\mathrm{O}$ and $\mathrm{O}-\mathrm{H}$ bending vibrations respectively (Liandong et al., 2012). The presence of peaks at $1625 \mathrm{~cm}^{-1}$ showed the presence of carbonyl groups $\mathrm{C}=\mathrm{O}$ of curcumin and the vibrational bands at around $1034 \mathrm{~cm}^{-1}$ can be due to $\mathrm{C}-\mathrm{O}$ stretching. The broad band showed in the range from 3200 to $3550 \mathrm{~cm}^{-1}$ is correlated to the stretching $\mathrm{O}-\mathrm{H}$. The ether bands of the pluronic can be obtained near $1100 \mathrm{~cm}^{-1}$ spectral region.

\section{Study the release rate of curcumin from the investigated composites}

It is interesting to evaluate the release rate of curcumin loaded with different concentrations on PVA. The synthesized PVA/ curcumin composites were examined by immersing samples in distilled water $(50 \mathrm{ml})$ at $25{ }^{\circ} \mathrm{C}$ for various time periods. Figure 4 represents the leaching rate of curcumin according to the time of exposure. The leaching rate was expressed by $\mu \mathrm{g} / \mathrm{mm}^{2}$ day $^{-1}$. The results illustrated that fast release was observed in the first days, their sustained release was extended at a higher rate for 17 days. After that, the rate of release was decreased up to 25 days (Gadekar et al., 2012). Although, the release behavior of the investigated formulas is similar to each other, the released amount was changed according to the curcumin content through the tested composites. The amount of release was increased as the loading of curcumin increased.

The type of release depended on the diffusion of distilled water inside the samples and dissolution of the soluble drug outside upon immersed in distilled water. The curcumin particles readily migrate from the matrix into the solution. The pore-like structures and some tortuous path were formed into the composite matrix and consequently, sufficient rapid curcumin release was obtained. These lead to the increase of the dispersion of water to the pore structures. This process was continued although the rate of lose usually varied according to the tortoise passes and growing pore structure (Rahman et al., 2014; Suresh et al., 2014).

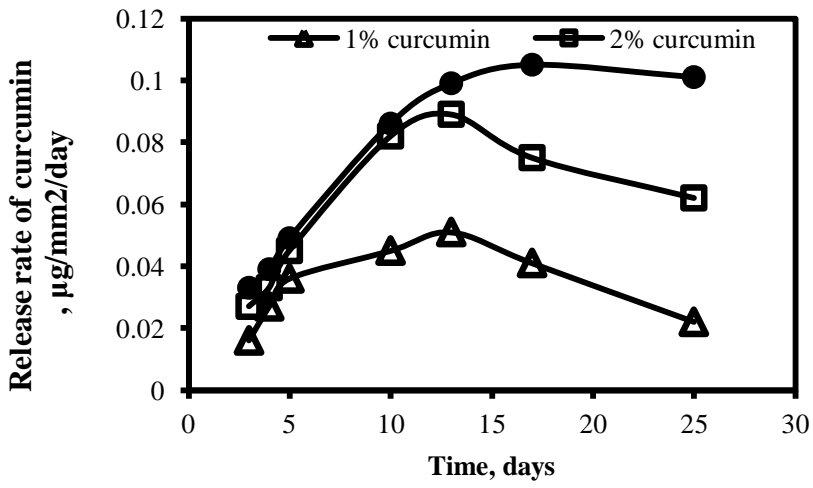

Fig. 4: The release rate of curcumin from the investigated PVA/ curcumin composites in distilled water

Study the release rate in aqueous media of different $\mathrm{pH}$ values

Figures 5 and 6 show the release pattern of curcumin. It is shown that the amount of release rate varied as the $\mathrm{pH}$ values of the media changed. The basic media and acidic media were adjusted using sodium hydroxide $(\mathrm{NaOH})$ and sulfuric acid $\left(\mathrm{H}_{2} \mathrm{SO}_{4}\right)$, respectively. The sustained release extending to about 25 days. The release rate was increased in basic, acidic and decreased in the neutral one. The release was decreased according to the following order: $\mathrm{pH} 9>\mathrm{pH} 4>\mathrm{pH} 7$. 


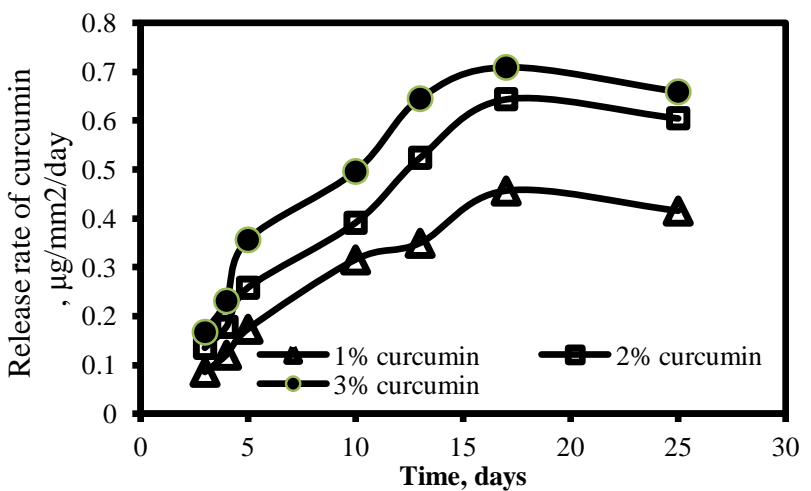

Fig 5: The release rate of curcumin from the investigated PVA/ curcumin composites in alkaline aqueous media

These behaviors were due to the lower solubility of curcumin in distilled water but the solubility increased in both acidic and alkaline media (Shah et al., 2008).

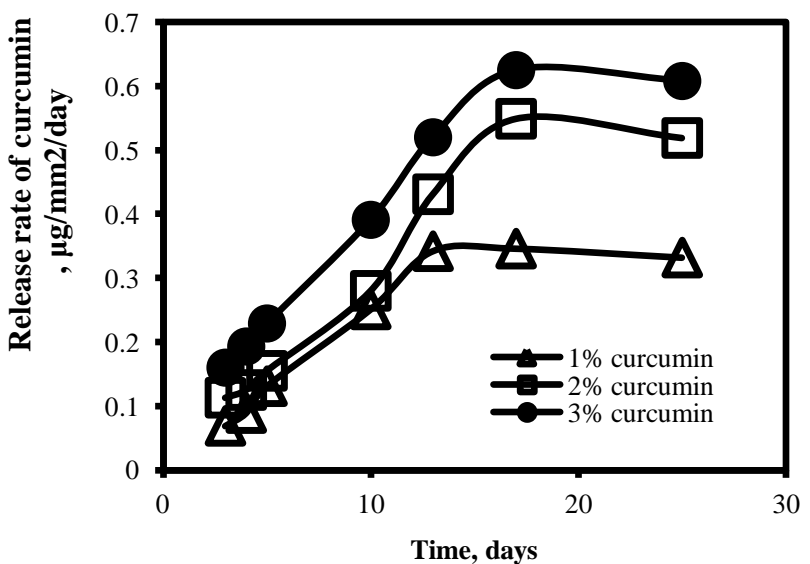

Fig. 6: The release rate of curcumin from the investigated PVA/ curcumin composites in acidic aqueous media

Also, it was observed that the release obtained from the sample containing (3\%) curcumin was higher than that released from the sample containing $(1 \%)$.

\section{The release kinetics of the curcumin}

The release kinetics of the PVA loaded with curcumin was studied according to the Higuchi's equation. Higuchi developed models (Kalam et al., 2007, Helaly et al., 2013) to determine the soluble dispersed curcumin material in the polymer matrix according to the following equation (8):

$$
M t=A(2 D T C s C o) 1 / 2
$$

Where, Mt is the accumulated amount of release curcumin at time $\mathrm{T}$; $\mathrm{A}$ is the surface area; D is the diffusion coefficient; Cs is the solubility of curcumin; Co is the initial dose of the drug; $\mathrm{T}$, the time. The leaching rate of curcumin was measured spectrophotometrically at varies aqueous media and the observed data are presented in Table 1. From Table 1, it can be shown that (D) of the investigated compounds are arranged as follows:

Basic medium >acidic medium $>$ neutral.

The more the diffusion coefficient is, the higher the release rate will be (Helaly et al., 2013). Consequently, the higher solubility of curcumin improved its diffusion coefficient and increased its release rate. Additionally, the higher degree of solubility of the drug is, the higher the release of the drug molecules will be (Helaly et al., 2013). Therefore, the diffusion was highly attributed to the characteristics of the composition of materials and the type of aqueous media.

Table 1: The diffusion coefficient (D) of curcumin released from theprepared PVA/curcumin compositesin different media and different concentrations

\begin{tabular}{cccc}
\hline Mediums & \multicolumn{3}{c}{ Curcumin } \\
\hline & $\mathbf{1 \%}$ & $\mathbf{2 \%}$ & $\mathbf{3 \%}$ \\
\hline $\mathrm{NaOH}$ & $2.346 \times 10^{-2}$ & $2.499 \times 10^{-2}$ & $2.739 \times 10^{-2}$ \\
$\mathrm{H}_{2} \mathrm{SO}_{4}$ & $1.559 \times 10^{-2}$ & $1.609 \times 10^{-2}$ & $1.638 \times 10^{-2}$ \\
Distilled $\mathrm{H}_{2} \mathrm{O}$ & $3.745 \times 10^{-4}$ & $5.639 \times 10^{-4}$ & $5.777 \times 10^{-4}$ \\
\hline
\end{tabular}

\section{The Kinetics of Drug Release}

The kinetic of the drug release was estimated from the relation between the cumulative release and time period (Vimala et al., 2011), according to an exponential equation (6) as shown in Figure $7 \mathrm{a}, \mathrm{b}$ and $\mathrm{c}$. Where, $\mathrm{Mt} / \mathrm{M} \infty$ represents the fractional drug release for $\mathrm{t}$ time, $\mathrm{k}$ is a constant which characterizes the drugpolymer system and $\mathrm{n}$ is an empirical parameter portraying the release mechanism.
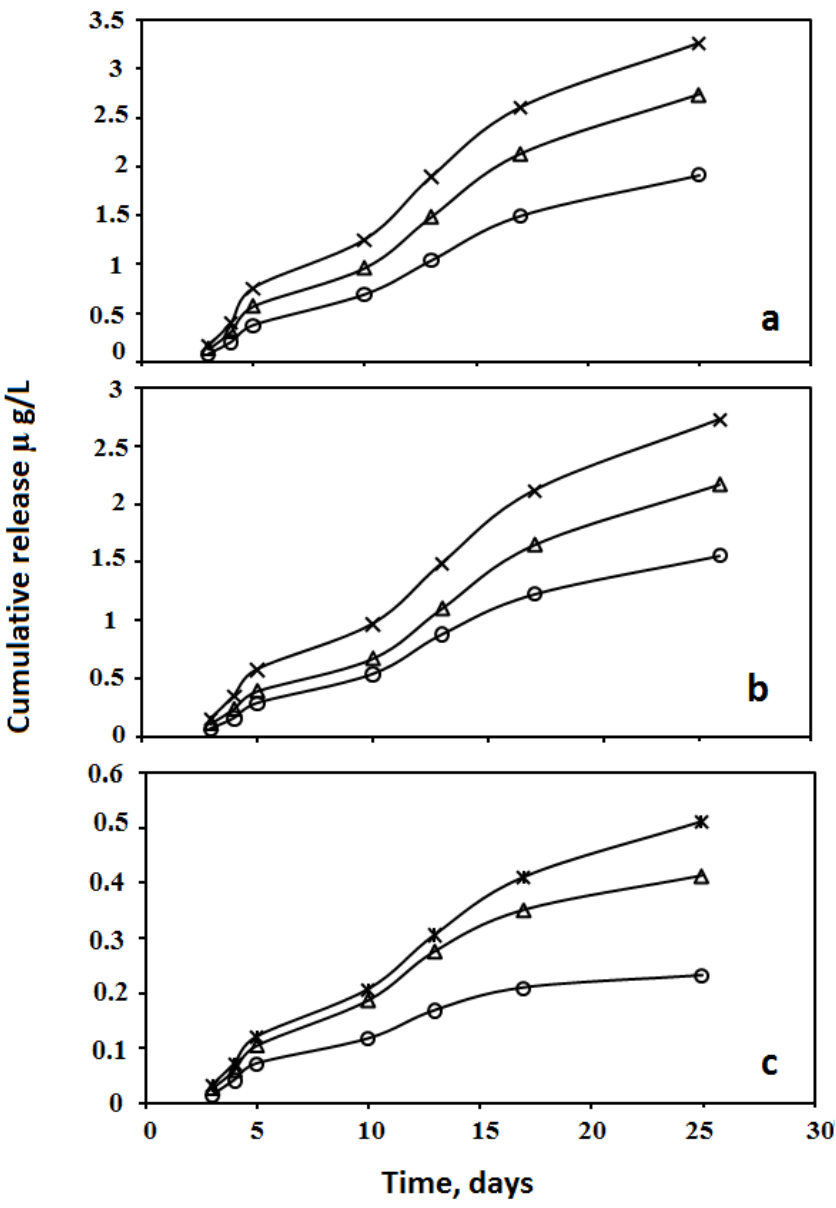

$\rightarrow 1 \%$ curcumin $\triangle 2 \%$ curcumin $* 3 \%$ curcumin Fig. 7: The cumulative release of curcumin from the prepared composites according to time in a- alkaline medium b-acidic medium c-distilled water 
The amounts of $\mathrm{n}$ and $\mathrm{k}$ for all the investigated composites are estimated and these data are given in Table 2.

The values of $\mathrm{k}$ and $\mathrm{n}$ are depended on the percentage of drug loading and the polymer content of the matrix. It was found that, the values of ' $k$ ' for the prepared composites containing various amount of drug ranging from 0.415 to 0.659 for alkaline medium, 0.332 to 0.608 for acidic medium and 0.022 to 0.101 for neutral medium, respectively. However, the composites which loaded with drug exposed ' $n$ ' values ranging from 0.401 to 0.475 foralkaline medium and 0.445 to 0.49 for acidic medium (Table 2). It is indicated that, the release exponent $\mathrm{n} \leq 0.5$ according to Fickian diffusion release from the sample. The $n$ values for neutral solution varying from 0.503 to 0.732 which shows that $0.5<\mathrm{n}<1.0$ for non-Fickian release (anomalous), this means that release of drug go ahead both diffusion and erosion controlled mechanisms (Chime et al., 2013) as well as when $\mathrm{n}=$ 0.5 , the drug diffused and released from the polymeric matrix with a quasi-Fickian diffusion mechanism (Parida et al., 2011; Chime et al., 2013).

Table 2: Release kinetic parameters of the prepared composites in different media and different concentrations.

\begin{tabular}{ccccccc}
\hline \multirow{2}{*}{ Mediums } & \multicolumn{3}{c}{ K } & \multicolumn{3}{c}{ n } \\
\cline { 2 - 7 } & $\mathbf{1 \%}$ & $\mathbf{2 \%}$ & $\mathbf{3 \%}$ & $\mathbf{1 \%}$ & $\mathbf{2 \%}$ & $\mathbf{3 \%}$ \\
\hline $\mathrm{NaOH}$ & 0.415 & 0.605 & 0.659 & 0.475 & 0.469 & 0.401 \\
$\mathrm{H}_{2} \mathrm{SO}_{4}$ & 0.332 & 0.519 & 0.608 & 0.49 & 0.466 & 0.445 \\
Distilled $\mathrm{H}_{2} \mathrm{O}$ & 0.022 & 0.062 & 0.101 & 0.732 & 0.589 & 0.503 \\
\hline
\end{tabular}

\section{The bioassay study of the released curcumin from the investigated polymer}

The antiproliferative activity of curcumin release from PVA loaded with curcumin was tested against human liver cancer cell line HEPG2.

Table 3 represents the efficacy of curcumin leached from the prepared composites on the growth inhibition and survival of HEPG2 liver cell line.

It is clear from the table that in vitro cytotoxic activity of the released curcumin showed sustained antiproliferative potency up to $30 \%$ growth inhibition against the human liver cancer cell line (HEPG2) which extended to 25 days. These results are in accordance with previous work indicated that curcumin selectively kills tumor cells (Ravindran et al., 2019).

Table 3: Effect of curcumin released from the prepared PVA/curcumin compositeson human liver cancer cell line (HEPG2).

\begin{tabular}{ccc}
\hline Release time Days & Surviving \% & Inhibition \\
\hline 3 & 70 & 30 \\
4 & 70 & 30 \\
5 & 73 & 27 \\
10 & 73 & 27 \\
13 & 72 & 28 \\
17 & 72 & 28 \\
25 & 71 & 29 \\
\hline
\end{tabular}

\section{CONCLUSION}

Slow release technique is a good mean for fighting cancer cell line. PVA was recommended as a good carrier for curcumin to sustained release over 25 days. The release rate for curcumin was affected by $\mathrm{pH}$ values of the aqueous media. The investigated biodegradable polymer loaded with curcumin composites (PVA/curcumin) gave a promising result on human liver cancer cell HEGP2.

\section{REFERENCES}

Chandy T, Sharma CP. Prostaglandin E1-Immobilized poly (vinyl alcohol) blended chitosan membranes: blood compatibility and permeability proper ties. J Appl Polym Sci, 1992; 44: 2145-2156.

Chime SA, Onunkwo GC, Onyishi II. Kinetics and Mechanisms of Drug Release from Swellable and Non Swellable Matrices: A Review. Res J Pharm Biol Chem Sci, 2013; 4(2): 97-103.

Cikrikci S, Mozioglu E, Y1lmaz H. Biological activity of curcuminoids isolated from Curcuma longa. Rec Nat Prod, 2008; 2: 1924.

Clemons C, Sedlmair J, Illman B, Ibach R, Hirschmugl C. Chemically imaging the effects of the addition of nanofibrillated cellulose on the distribution of poly(acrylic acid) in poly(vinyl alcohol). Polym, 2013; 54(8): 2058-2061.

Douglass BJ, Clouatre DL. Beyond yellow curry: assessing commercial curcumin absorption technologies. J Am Coll Nutr, 2015; 34(4): 347-358.

Dutta AK, Ikiki E. Novel drug delivery systems to improve bioavailability of curcumin. J Bioequiv Availab, 2013; 6: 1-9.

Gadekar R, Saurabh MK, Thakur GS, Saurabh A. Study of formulation, characterisation and wound healing potential of transdermal patches of curcumin. Asian J Pharm Clin Res, 2012; 5: 225-230.

Helaly FM, El-Nashar DE, Khalaf AI, Abdel Hamid HF, Abd El-Moez SI, Soliman AM. Slow Release of 5-fluorouracil from Natural Polymeric Composites as Controlled Drug Delivery. Int J Pharm Sci Rev Res, 2015; 30(1): 137-142.

Helaly FM, Khalaf AI, El-Nashar DE. Starch cellulose acetate co-acrylate (SCAA) polymer as a drug carrier. Res Chem Intermed, 2013; 39: 3209-3220.

Helaly FM, Mourad RM, Abdel Hamid HF, Abd El-Moez, SI, Soliman AM. Monitoring the efficiency of 5- fluorouracil released from synthesized composite of poly $\beta$ - amino ester as antitumor and antibacterial. WJPR, 2015; 4(7): 205-213.

Higuchi T. Mechanism of sustained action medication. Theoretical analysis of rate of release of solid drugs dispersed in solid matrices. J Pharm Sci, 1963; 52(12): 1145-1149.

Kalam MA, Humayun M, Parvez N, Yadav S, Garg A, Amin S, Sultana Y, Ali A. Release kinetics of modified pharmaceutical dosage forms. A review. C J Pharm Sci, 2007; 1: 30-35.

Kulkarni AR, Soppimath KS, Aminabhavi TM. Controlled release of diclofenac sodium from sodium alginate beads crosslinked with glutaraldehyde. Pharm Acta Helv, 1999; 74: 29-36.

Liandong H, Yanhong J, Feng N, Zheng J, Xun Y, Kuiliang J. Preparation and enhancement of oral bioavailability of curcumin using microemulsions vehicle. J Agric Food Chem, 2012; 60: 7137-714.

Mallapragada SK, Peppas NA. Dissolution nechanism of semi crystalline poly (vinyl alcohol) in water. J Polym Sci, Part B: Polym. Phys, 1996; 34: 1339- 1349.

Mandal V, Mohan Y, Hemalatha S. Optimization of curcumin extraction by microwave assisted in vitro plant cell bursting by orthogonal array designed extraction process and HPTLC analysis. Pharmacogn Mag, 2007; 3: 132-138.

Marson FJ. Anti-fouling paints. I. Theoretical approach to leaching of soluble pigments from insoluble paint vehicles. J Appl Chem, 1969; 19: 93-99.

Nagpal M, Sood S. Role of curcumin in systemic and oral health: An overview. J Nat Sci Biol Med. 2013; 4(1): 3-7.

Parida UK, Nayak AK, Binhani BK, Nayak PL. Synthesis and characterization of chitosan-polyvinyl alcohol blended with cloisite 30B 
for controlled release of the anticancer drug curcumin. J Biomater Nanobiotechnol, 2011; 2(4): 414-425.

Rahman MH, Ramanathan M, Sankar V. Preparation, characterization and in vitro cytotoxicity assay of curcumin loaded solid lipid nanoparticle in IMR32 neuroblastoma cell line. Pak J Pharm Sci, 2014; 27(5): 1281-1285.

Ravichandran R. Studies on dissolution behavior of nanoparticulate curcumin formulation. Adv Nanopart, 2013; 2: 51-59.

Ravindran J, Prasad S, Aggarwal BB. Curcumin and Cancer Cells: How Many Ways Can Curry Kill Tumor Cells Selectively? AAPS J. 2009; 11: 495-510.

Ritger RL, Peppas NA. A simple equation for description of solute release II. Fickian and anomalous release from swellable devices. J Controlled Release Journal of Controlled Release, 1987; 5: 37-42

Sahoo S, Sasmal A, Nanda R, Phani AR, Nayak PL. Synthesis of chitosan-polycaprolactone blend for control delivery of ofloxacin drug. Carbohydr. Polym, 2010; 79: 106-113.

Shah CP, Mishra B, Kumar M, Priyadarsini KI, Bajaj PN. Binding studies of curcumin to polyvinyl alcohol/ polyvinyl alcohol hydrogel and its delivery to liposomes. Curr Sci, 2008; 95(10): 1426-1432.

Sharma K, Agrawal SS, Gupta M. Development and validation of uv spectrophotometric method for the estimation of curcumin in bulk drug and pharmaceutical dosage forms. Int J drug dev res, 2012; 4(2): 375 380 .

Skehan P, Storeng R, Scudiero D, Monks A, McMahon J, Vistica D, Warren J, Bokesch H, Kenney S, Boyd MJ. New colorimetric cytotoxicity assay for anticancer drug screening. J Natl Cancer Inst, 1990; 82(13): 1107-1112.

Steffi PF, Srinivasan M. Preparation, characterization and stabilization of curcumin nanosuspension. Int J PharmTech Res, 2014; 6(2): $842-849$

Suresh K, Yogesh C, Priyanka B, Khushbu S, Manisha B. Enhancement of solubility and dissolution rate of curcumin by solid dispersion technique. Int Res J Pharm, 2014; 4(5): 226 232.

Vimala K, Mohan YM, Varaprasad K, Redd NN, Ravindra S, Naidu NS, Raju KM. Fabrication of curcumin encapsulated chitosan-PVA silver nanocomposite films for improved antimicrobial activity. J Biomater Nanobiotechnol, 2011; 2: 55-64.

$\mathrm{Xu} \mathrm{G}$, Sunada $\mathrm{H}$. Influence of formation changes on drug release kinetics. Chem Pharm Bull, 1995; 43: 483-487.

\section{How to cite this article:}

El-Nashar DE, Rozik NN, Soliman AM, Helaly FM. Study the release kinetics of curcumin released from $\mathrm{PVA} /$ curcumin composites and its evaluation towards hepatocarcinoma. J App Pharm Sci, 2016; 6 (07): 067-072. 